Article

\title{
Application of a Natural Antioxidant from Grape Pomace Extract in the Development of Bioactive Jute Fibers for Food Packaging
}

\author{
Cristina Cejudo-Bastante, Paloma Arjona-Mudarra, María Teresa Fernández-Ponce, Lourdes Casas (D), \\ Casimiro Mantell * (D), Enrique J. Martínez de la Ossa (D) and Clara Pereyra (D)
}

Chemical Engineering and Food Technology Department, Wine and Agrifood Research Institute (IVAGRO), University of Cádiz, Puerto Real, 11519 Cádiz, Spain; cristina.cejudo@gm.uca.es (C.C.-B.); paloma.arjonamudarra@alum.uca.es (P.A.-M.); teresafernandez.ponce@gm.uca.es (M.T.F.-P.); lourdes.casas@uca.es (L.C.); enrique.martinezdelaossa@uca.es (E.J.M.d.l.O.); clara.pereyra@uca.es (C.P.)

* Correspondence: casimiro.mantell@uca.es

Citation: Cejudo-Bastante, C.; Arjona-Mudarra, P.; Fernández-Ponce, M.T.; Casas, L.; Mantell, C.; Martínez de la Ossa, E.J.; Pereyra, C. Application of a Natural Antioxidant from Grape Pomace Extract in the Development of Bioactive Jute Fibers for Food Packaging. Antioxidants 2021, 10, 216. https://doi.org/ 10.3390/antiox10020216

Received: 7 January 2021

Accepted: 29 January 2021

Published: 2 February 2021

Publisher's Note: MDPI stays neutral with regard to jurisdictional claims in published maps and institutional affiliations.

Copyright: (c) 2021 by the authors. Licensee MDPI, Basel, Switzerland. This article is an open access article distributed under the terms and conditions of the Creative Commons Attribution (CC BY) license (https:// creativecommons.org/licenses/by/ $4.0 /)$.

\begin{abstract}
There is an increasing demand for the use of new food packaging materials. In this study, natural jute fibers impregnated with a Petit Verdot Red Grape Pomace Extract (RGPE) was proposed as a new active food packaging material. Pressurized Liquid Extraction (PLE) and Enhanced Solvent Extraction (ESE) techniques were employed to obtain the bioactive RGPE. Afterward the supercritical solvent impregnation conditions to obtain RGPE-natural jute fibers were studied, by varying pressure, modifier percentage and dried RGPE mass. PLE technique offered the highest bioactive extract at $20 \mathrm{MPa}, 55^{\circ} \mathrm{C}, 1 \mathrm{~h}$ residence time using $\mathrm{C}_{2} \mathrm{H}_{5} \mathrm{OH}: \mathrm{H}_{2} \mathrm{O}(1: 1 \mathrm{v} / \mathrm{v})$, providing an $\mathrm{EC} 50$ of $3.35 \pm 0.25$ and antibacterial capacity against Escherichia coli, Staphylococcus aureus and Pseudomonas aeruginosa (MIC of 12.0, 1.5 and $4.0 \mathrm{mg} / \mathrm{mL}$ RGPE respectively). The natural jute fibers impregnated with $3 \mathrm{~mL}$ of that RGPE $\left(90 \mathrm{mg} / \mathrm{mL}\right.$ ) at $50 \mathrm{MPa}$ and $55^{\circ} \mathrm{C}$ generated the most efficient packing material with regards to its food preservation potential.
\end{abstract}

Keywords: active packaging; food preservation; supercritical solvent impregnation; vinification by-products; natural fibers

\section{Introduction}

Grape cultivation is one of the main and most widespread agro-economic activities in the whole world, mostly used for winemaking, with an official global production in 2019 in excess of 77 million tons according to FAO statistics. Wine production generates enormous amounts of by-products. Its valorization is mainly represented by the production of soil fertilizers, fermentation substrate for biomass production and livestock feed [1]. However, there are certain restrictions on the reuse of these by-products. For example, the phytotoxicity of certain polyphenols could have an antimicrobial effect during composting, which would impair their use for such purpose. Regarding their use as cattle feed, some animals have shown intolerance to certain components, such as condensed tannins, which negatively affect their digestion [2]. However, grape vinification by-products have a high content in bioactive compounds, especially polyphenols and condensed tannins (proanthocyanidins) or even anthocyanins, in the case of red grape pomace [3], which represent a source of antioxidant and antimicrobial rich compounds of interest for the manufacturing of different cosmetic, pharmacological or food products [4,5]. For instance, it has been reported the use of aqueous extracts of red grape pomace in the elaboration of meat products due to their antioxidant and antimicrobial properties, particularly against mesophiles, psycrotrophics and fecal microbiota [6-8]. However, the applicability of RGPE go beyond their direct addition in food formulation and it has been also investigated in material engineering. Besides its use as a natural dyeing colorant for wood, silk, cotton, polyamide 
or acrylic fabrics [9-11], anthocyanins and proanthocyanidins from red grape and other sources have been recently used as $\mathrm{pH}$-sensitive compounds in intelligent packaging and as an active substance in active film-packaging formulation [12-15]. For example, Kurek et al. evaluated the antioxidant properties of chitosan and carboxymethyl cellulose films enriched with blueberry and red grape pomace extracts [16]. Bi et al. completed a deep study and demonstrated not only the antioxidant properties but also the antimicrobial ones of a chitosan-proanthocyanidins film against Escherichia coli, Salmonella spp., Staphylococcus aureus and Listeria monocytogenes during in vitro experiments [17]. In agreement, Qin et al. discuss the same properties on biodegradable films enriched with purple corn extract [18] and Lycium ruthenicum Murr. [19], which demonstrated, in that case, anthocyanins' preservative effect on pork meat. Moreover, $\mathrm{Xu}$ et al. evaluated the antimicrobial capacity against $S$. aureus and L. monocytogenes of the Cabernet Franc and Viognier grape pomace extracts used for the production of starch films [20].

Today's society as well as some governmental regulations, point the absolute necessity to replace plastic materials by other biodegradable alternative constituents. In the food field, the highest challenge is the replacement of plastic-packaged and net-packaged products by other more environmentally friendly alternatives. In this sense, the functionalization of natural fibers by supercritical fluids seem a reliable alternative due to its resistant nature grants a lower modification of their structure under supercritical conditions. Among them, jute (Corchorus capsularis) is one of the most natural fibers used in food packaging, because it has been traditionally used to pack bulk vegetables and beans since decades. It has been used for different applications such as packaging paper, decorations, reinforcement for polymers, construction, furniture, automotive applications [21,22]. Although some research studies on fabrics, such as cotton, with natural extracts for biomedical application have been reported [23-26], as far as we know, there is scarce research on the use of jute in the food industry. The literature found on this subject is focused on the use of natural fibers as a reinforcing filler in composites $[27,28]$, because their improvement of strength, stiffness and better moisture absorption [29]. Just to mention an example, Jawaid et al. [30] developed a material based on jute in combination with oil palm fruit bunches and obtained a resistant composite material that could be used for different applications. Moreover, Gangopadhyay et al. [31] developed a polypropylene (PP) and superabsorbent fiber (SAF) based on technical fabric, to be used as a potential packaging material to transport fresh fruit and vegetables. Furthermore, Chatterjee et al. (2020) developed a laminated packaging made of jute fibers and PP by thermal processing [32]. However, no active substances were included in any of those formulations.

In view of the literature and the great potential of both natural fibers and RGPE for food industry, this study intends to analyze the development of an alternative jute food-packaging material with bioactive properties thanks to its impregnation with RGPE. Among the different techniques reported in the bibliography, the supercritical solvent impregnation (SSI) is the one that is having a greater scientific impact at the moment. On one hand, $\mathrm{scCO}_{2}$ offer advantages in comparison to other traditional techniques such as casting or extrusion, like their applicability to different matrices (wounds, polymers, particles, etc.) or that being a functionalization technique after the polymerization of the matrix do not compromise the polymerization step [33]. Besides, it offers the possibility to combine both SFE and SSI in a continuous system [34,35]. Numerous investigations have focused on the supercritical impregnation of natural extracts, such as thyme [36], clove $[37,38]$ or oregano essential oils [39] among others, into synthetic polymeric films.

In the present study, the RGPE is obtained by a Pressurized Liquid Extraction (PLE) and Enhanced Solvent Extraction (ESE) has been used as supercritical extraction techniques, due to they combine the use of polar co-solvents and $\mathrm{scCO}_{2}$ to increase the extraction yield of plant extracts [40,41].

The objective of the present study is both analyze the extraction and impregnation process using high pressure techniques. Extraction yield and antioxidant capacity levels of the RGPE obtained by ESE and PLE were compared by varying different pressure 
(10 and $20 \mathrm{MPa}$ ) temperature $\left(55-70{ }^{\circ} \mathrm{C}\right)$ and co-solvent $\left(\mathrm{C}_{2} \mathrm{H}_{5} \mathrm{OH}\right.$ or $\left.\mathrm{C}_{2} \mathrm{H}_{5} \mathrm{OH}: \mathrm{H}_{2} \mathrm{O}\right)$ conditions. The antimicrobial capacity of the chosen extract against food-borne pathogens was analyzed prior to its impregnation into jute fibers, in order to obtain active fabrics with potential preservative properties as food packaging. For this purpose, the influence of some supercritical impregnation parameters were studied, such as pressure $(10-50 \mathrm{MPa})$ percentage of modifier $(2.8,4.8$ and $6.7 \%)$ and amount of dried RGPE $(28.8$ and $270 \mathrm{mg})$ in the impregnation vessel.

\section{Materials and Methods}

\subsection{Chemical Reagents, Raw Materials and Bacterial Samples}

The chemical reagents and materials used in this work are presented in Table 1. Red grape pomace (RGP) of the Petit Verdot variety was supplied by "Bodegas Luis Pérez" (Jerez de la Frontera, Spain). It was obtained immediately after the vinification process and it was dried in an oven at $60^{\circ} \mathrm{C}$. Prior to the extraction process, it was grinded with a blender to reduce particle size. Finally, natural jute fibers with a grammage of $305 \mathrm{~g} / \mathrm{m}^{2}$ was supplied by Deyute (Tejijut S.L.U, Crevillente (Alicante, Spain)).

Table 1. Chemical regents and microbial strains.

\begin{tabular}{cc}
\hline Reagent & Supplier \\
\hline Carbon dioxide (99.99\%) & Abello-Linde S.A. (Barcelona, Spain). \\
2,2-diphenyl-1-picrylhydrazyl (DPPH) & Sigma-Aldrich (Steinheim, Germany) \\
Lennox LB agar & Conda Laboratories (Torrejón de Ardoz, Spain) \\
Dimethyl sulfoxide (DMSO) & Panreac (Barcelona, Spain) \\
Phenolic standards (gallic acid, quercetin and cyanidin) & Sigma-Aldrich (Steinheim, Germany) \\
Lysogenic Broth (LB) with 10 g/L tryptone, 5 g/L NaCl and 5 g/L yeast extract & Sigma-Aldrich (Steinheim, Germany) \\
Escherichia coli (CECT101) & Spanish Type Culture Collection (CECT, Valencia, Spain) \\
Pseudomonas aeruginosa (ATCC 9027) & Microbiologics Inc. (Saint Cloud, MN, USA) \\
Staphylococcus aureus (ATCC 6538) & Microbiologics Inc. (Saint Cloud, MN, USA) \\
\hline
\end{tabular}

\subsection{High-Pressure Extraction of RGPE}

The extractions were carried out in a high-pressure equipment (Thar Technologies SF100, Pittsburgh, PA, USA) described in a previous work [42] (Figure 1). $20 \mathrm{~g}$ of RGP was loaded into a paper filter cartridge and it was installed inside the extraction vessel. When the pre-set temperature conditions were achieved, the co-solvent and the $\mathrm{CO}_{2}$ supply were pumped until the desired pressure was reached. Then, the BPR opened to let the extract enter the cyclonic separator. In the PLE procedure, no $\mathrm{CO}_{2}$ process-line was necessary, since only liquid solvents are used.

The extraction conditions were selected according to the results obtained in previous studies [41]. First, an ESE process was completed during $1 \mathrm{~h}$ using $\mathrm{CO}_{2}$ and ethanol pumped at $5 \mathrm{~g} / \mathrm{min}$ each one, with a total flow rate of $10 \mathrm{~g} / \mathrm{min}$. Pressure and temperature were studied at 10 and $20 \mathrm{MPa}$, at 55 and $70{ }^{\circ} \mathrm{C}$ respectively. PLE was carried out at the best pressure and temperature conditions previously defined by ESE, using pure ethanol and a mixture of $\mathrm{C}_{2} \mathrm{H}_{5} \mathrm{OH}: \mathrm{H}_{2} \mathrm{O}(1: 1 v / v)$ as solvents. The extraction yields were calculated (Equation (1)):

$$
\text { Extraction yield }=\frac{m_{R P G E}(g)}{m_{R G P}(g)} \times 100
$$

where $m_{R G P E}$ is the mass of the extract obtained and $m_{R G P}$ is the mass of red grape pomace extracted. 


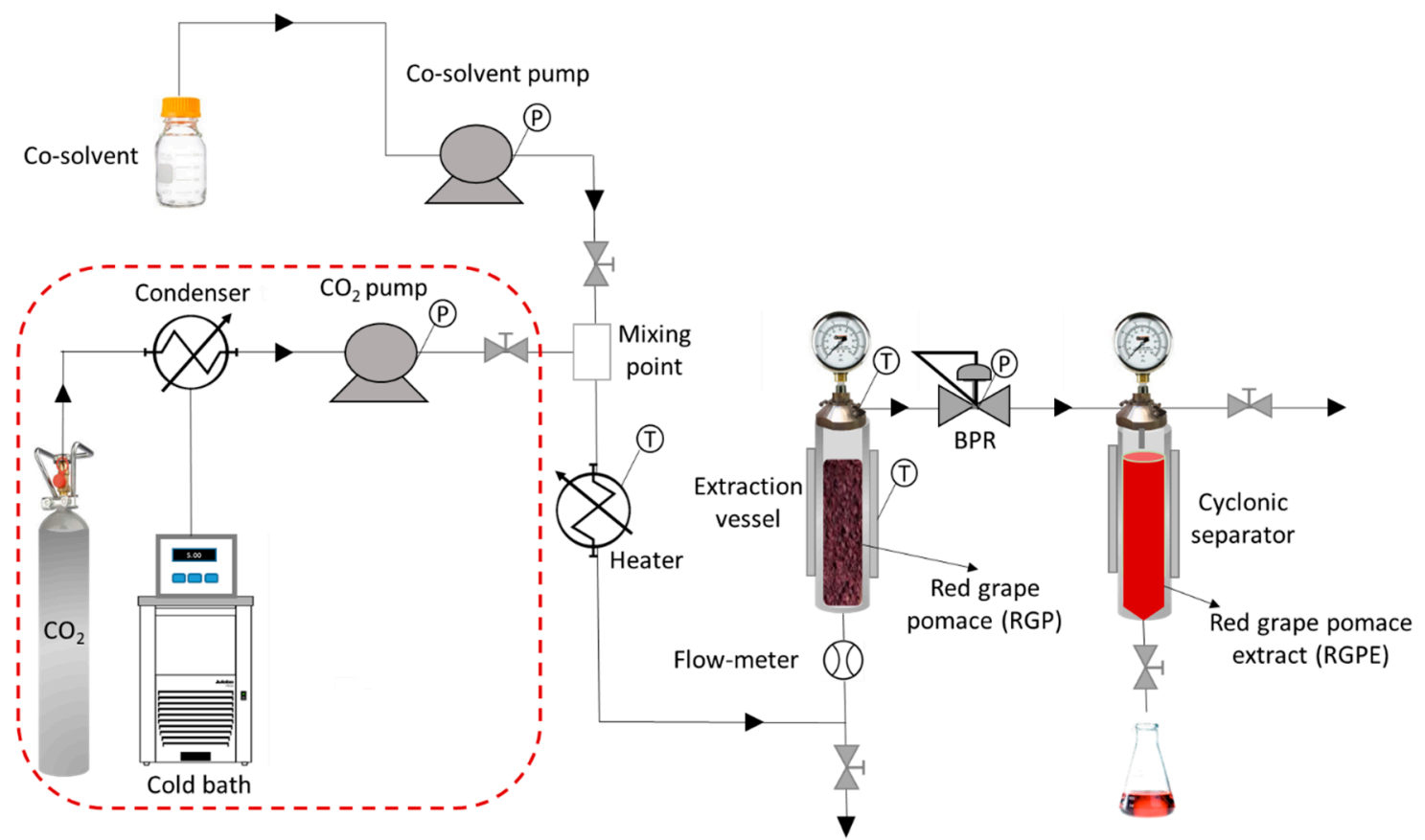

Figure 1. High Pressure Extraction equipment flowchart. The $\mathrm{CO}_{2}$ process-line (within the red dot-line) is not used in PLE processes.

\subsection{Supercritical Impregnation of Natural Jute Fibers with RGPE}

The impregnation process was carried out in the same high-pressure set-up described in Section 2.2, but using a thermostatic flat bottomed impregnation vessel (104 mL) (Waters Corp., Milford, MA, USA). A certain amount of RGPE was poured into the vessel. A magnetic stirrer, running at $60 \mathrm{rpm}$, is installed at the bottom of the vessel to aid to the dissolution of the extract. Then, it was introduced a stand that holds a $5 \mathrm{~cm}$ wide rounded-shape sample of jute natural fibers horizontally. The impregnation procedures were carried out in batch mode. $\mathrm{CO}_{2}$ was first pumped at $10 \mathrm{~g} / \mathrm{min}$ until the desired pressure conditions were reached. Then, the $\mathrm{CO}_{2}$ flow was stopped and the system pressure was maintained until the impregnation time $(1 \mathrm{~h})$ was over. The system was rapidly depressurized $(10 \mathrm{MPa} / \mathrm{min})$ to obtain the impregnated jute fibers (IJF). The depressurization rate flow acted also as drying agent, so any further drying step of the fabric was required.

Three sets of experiments were carried out to determine the influence of some variables on the process (Table 2). The optimal impregnation conditions in each experiment were established according to the impregnation loading and antioxidant capacity of the impregnated natural fibers.

Table 2. Summary of the impregnation experiments' conditions.

\begin{tabular}{|c|c|c|c|c|c|c|c|}
\hline Experiment & $\begin{array}{c}\mathbf{P} \\
(\mathrm{MPa})\end{array}$ & $\begin{array}{c}\mathrm{T} \\
\left({ }^{\circ} \mathrm{C}\right)\end{array}$ & $\begin{array}{l}\text { Dried RGPE } \\
\text { (mg)* }\end{array}$ & \% RGPE & $\begin{array}{c}\% \text { Modifier }(v / v)^{* *} \\
\left(\mathrm{C}_{2} \mathrm{H}_{5} \mathrm{OH}: \mathrm{H}_{2} \mathrm{O}\right)\end{array}$ & $\begin{array}{c}\text { Molar Ratio } \\
\text { (n } \mathrm{CO}_{2} / \mathrm{n} \text { Modifier) }\end{array}$ & $\begin{array}{c}\text { Modifier } \\
\text { Volume (mL) }\end{array}$ \\
\hline \multirow[t]{2}{*}{1} & 10 & 55 & 28.8 & 9.6 & 2.8 & 6.88 & 3 \\
\hline & 50 & & & & & 20.09 & \\
\hline \multirow[t]{3}{*}{2} & 50 & 55 & 28.8 & 9.6 & 2.8 & 20.09 & 3 \\
\hline & & & 46.1 & & 4.8 & 10.73 & 5 \\
\hline & & & 67.2 & & 6.7 & 7.89 & 7 \\
\hline 3 & 50 & 55 & 270 & 90 & 2.8 & 20.09 & 3 \\
\hline
\end{tabular}

* Adjusted by drying RGPE using a rotavapor and then re-dissolving into the desired amount of modifier. ${ }^{* *}$ Calculated respecting the total volume of the vessel. 


\subsection{Analysis of the Bioactivity of the Extracts and the IJF Samples}

\subsubsection{Antioxidant Capacity}

The antioxidant capacity of samples was evaluated by means of a DPPH assay considering the methods described by Brand-Williams [43] and Scherer and Godoy [44]. The reaction of the $\mathrm{N}$. radical of DPPH in the presence of the extract is controlled by reducing the absorbance at $515 \mathrm{~nm}$. To perform the analysis, $0.1 \mathrm{~mL}$ of the extract at different concentrations was added to $3.9 \mathrm{~mL}$ of the $6 \times 10^{-5} \mathrm{M} \mathrm{DPPH}$ ethanolic solution. The absorbance was measured every 2 min during $4 \mathrm{~h}$ until the plateau was reached. The tests were performed in triplicate.

The concentration of the remaining DPPH after the test was determined using a DPPH calibration line previously determined (Equations (2) and (3)):

$$
\begin{gathered}
A b s=10089 M+0.0085 ; \mathrm{R}^{2}=0.9994 \\
\text { RemainingDPPH }=\frac{C_{D P P H f}}{C_{D P P H i}} \times 100
\end{gathered}
$$

where $M$ is the molar concentration of DPPH, $C_{D P P H i}$ is the concentration of DPPH at the initial time and $C_{D P P H}$ is the concentration of DPPH at time $t$. By plotting the values of the remaining \% DPPH in stationary state versus the concentration of the extract at each point, the EC50 value (efficient concentration) can be graphically determined. The extract with the highest antioxidant properties was further characterized in terms of antibacterial activity and was used for the impregnation process.

The antioxidant capacity and loading of impregnated samples were determined using the method described by Cejudo et al. [33] with some changes. A specific amount of the impregnated natural fibers was introduced in $3 \mathrm{~mL}$ of ethanol and was sonicated during $30 \mathrm{~min}$ in order to extract the impregnated compounds. Then, the solvent was evaporated in a rotavapor and it was replaced by $4 \mathrm{~mL}$ of the DPPH reagent at $6 \times 10^{-5} \mathrm{M}$ in ethanol. The reaction was kept in the dark for $4 \mathrm{~h}$ and the reduction of the absorbance was determined as \% (Equation (5)). The results were expressed as \%I/100 mg natural fibers. To calculate the antioxidant activity, the inhibition percentage (\%I) (Equation (5)) versus the extract concentration at the pleateau was plotted, obtaining Equation (6):

$$
\begin{gathered}
I=\frac{A b s_{i}-A b s_{f}}{A b s_{i}} \times 100 \\
\% I=-0.3427 C^{2}+10.596 C+15.665 ; R^{2}=0.9989
\end{gathered}
$$

where $A b s_{i}$ is DPPH absorbance at the initial time, $A b s_{t}$ is DPPH absorbance at time $t$ measured at $515 \mathrm{~nm}$, and $C$ is the RGPE concentration that results in a particular \%I at each point.

In order to calculate the impregnation loading of the natural fibers samples, the concentration of RGPE was calculated expressing the results as $\mu \mathrm{g}$ RGPE/100 mg natural fibers.

\subsubsection{Antibacterial Capacity of the RGPE and the IJF Samples}

The antibacterial capacity was tested against E. coli, P. aeruginosa and S. aureus, by agar dilution method in $60 \mathrm{~mm}$ Petri plates using 0.375, 0.75, 1.5, 3, 4, 5, 6, 8, 10 and $12 \mathrm{mg} / \mathrm{mL}$ of RGPE. The test was carried out in triplicate and a solution of DMSO and distilled water $(1: 1 \mathrm{v} / \mathrm{v})$ was used as the negative control. The plates were inoculated with $0.1 \mathrm{~mL}$ of a $1.5 \times 10^{6} \mathrm{UFC} / \mathrm{mL}$ inoculum. After a $24 \mathrm{~h}$ incubation at $37^{\circ} \mathrm{C}$, the minimum inhibitory concentration (MIC) in each bacterial culture was determined.

In the case of the impregnated samples, their inhibition properties were assessed in a liquid medium. Two different amounts of impregnated natural fibers (50 and $100 \mathrm{mg}$ ) were used in order to determine their inhibitory properties in two ranges. Samples were sterilized by UV and then introduced in a $5 \mathrm{~mL}$ sterilized tube with liquid LB propagation 
medium. $24 \mathrm{~h}$ were allowed for the compounds to diffuse in the culture media, and then the blank of each tube medium was measured at $625 \mathrm{~nm}$. The extract compounds were considered to have diffused completely, achieving concentrations in the media of ca. $0.07 \mathrm{mg} / \mathrm{mL}$ and $0.14 \mathrm{mg} / \mathrm{mL}$, when using 50 and $100 \mathrm{mg}$ of IJF respectively. Then, the tubes were inoculated at $1.5 \times 10^{6} \mathrm{UFC} / \mathrm{mL}$ and incubated $\left(24 \mathrm{~h} / 37^{\circ} \mathrm{C}\right)$. Absorbance was measured at $625 \mathrm{~nm}$ to determine bacterial growth inhibition (Equation (6)).

$$
\text { Inhibition }=\left(1-\frac{C_{f}}{C_{i}}\right) \times 100
$$

where $C_{f}$ is the cell concentration of samples and $C_{i}$ is the cell concentration in the positive control containing non-impregnated natural fibers.

\subsection{Phenolic Characterization of RGPE and Impregnated Jute Fibers by UPLC-ESI-TOF-MS}

The phenolic characterization of both the RGPE and the impregnated fibers have been carried out by ultra-performance liquid chromatography (UHPLC) coupled to quadrupoletime-of-flight mass spectrometry (QToF-MS) (Xevo G2 QToF, Waters Corp.). The chromatographic method followed have been previously described by Cejudo et al. (2018) [45], with some modifications. To recover phenolic compounds, certain amount of IJF was introduced into $10 \mathrm{~mL}$ of ethanol and sonicated during $30 \mathrm{~min}$. Then, the fraction was evaporated in a rotavapor and diluted in $1 \mathrm{~mL}$ of ethanol and filtered through $0.22 \mu \mathrm{m}$ prior to the chromatographic analysis. Not impregnated jute fibers have been also analysed in order to eliminate interferences in the phenolic determination, so the signals detected were used as blank of the impregnated jute fiber signals. Identification of compounds was carried out considering the molar mass, the molecular formula and the presence of compounds reported in literature [46,47]. Analysis have been done in duplicate.

The column employed in the analysis was an Acquity UPLCr BEH C18 column (50 mm $\times 2.1 \mathrm{~mm}$ i.d., $1.7 \mathrm{~mm}$ particle size, Waters Corporation). The mobile phase is comprised by a phase $\mathrm{A}$ (water with $0.1 \%$ formic acid) and a phase B (acetonitrile with $0.1 \%$ formic acid) working with a flow rate of $0.6 \mathrm{~mL} / \mathrm{min}$. Analysis was started at $98 \%$ phase A for $0.3 \mathrm{~min}$, changing to $65 \%$ at $1.5 \mathrm{~min}$ later. Then solvent B achieved the $100 \%$ after $1.5 \mathrm{~min}$, maintaining that proportion during $1 \mathrm{~min}$. Then, the B percentage decreased until $2 \%$ and was maintained for a minute. The total method time was $5 \mathrm{~min}$. Electrospray was operated in full scan analysis (100-1000 Da), working in negative ionization mode for the determination of phenolic acids, flavanols and flavonols, and in positive ionization mode for anthocyanin determination. Three calibration lines were carried out to quantify three different families of phenolic compounds: phenolic acids (Equation (7)), flavonols and flavanols (Equation (8)), and anthocyanins (Equation (9)):

$$
\begin{aligned}
& \text { Gallic acid }=1813 x-1235.2 ; R^{2}=0.9997 \\
& \text { Quercetin }=221.68 x-737.86 ; R^{2}=0.9902 \\
& \text { Cyanidin }=48.521 x-248.2 ; R^{2}=0.9951
\end{aligned}
$$

\subsection{Scanning Electron Microscopy (SEM)}

Natural fibers were visually evaluated by SEM (Quanta 200, FEI, Hillsboro, OR, USA) to verify the presence of the impregnated extract in the fibers. Samples analyzed were those obtained at the most convenient impregnation conditions. Fibers were coated with a gold layer (15 $\mu \mathrm{m}$ thick) and were submitted to a $20 \mathrm{kV}$ voltage.

\section{Results and Discussions}

\subsection{RGPE Bioactivity}

The extraction yield and the antioxidant activity of the extracts obtained is collected in Figure 2. Respecting to the extraction yield of the extracts obtained by ESE, under 
isobaric conditions an increase in temperature from $55^{\circ} \mathrm{C}$ to $70{ }^{\circ} \mathrm{C}$ hindered the extraction process. This behaviour can be attributed to the fact that the density of the mixture $\mathrm{CO}_{2}+$ $\mathrm{C}_{2} \mathrm{H}_{5} \mathrm{OH}$ decreased [48], which would intervene in the extraction of high-weight molecules as anthocyanins. Another possible explanation to this behaviour is the possibility of being in a retrograde solubility zone above this temperature. On the contrary, under isothermal conditions, an increase in pressure from 10 to $20 \mathrm{MPa}$ improved extraction thanks to the higher density level of the mixture. Regarding to the extract bioactivity, the extract obtained at $20 \mathrm{MPa}$ and $55{ }^{\circ} \mathrm{C}$ showed a significantly higher EC50 than the rest. At $10 \mathrm{MPa}$, the influence of the temperature was not as evident as the samples obtained at $20 \mathrm{MPa}$, where the increase of the temperature decreases the antioxidant capacity of the extracts. Mantell et al. [49] previously reported a higher extraction yield of anthocyanins from the same raw material in ESE when using methanol in higher \% organic co-solvent instead of water, obtaining better recovering at $10 \mathrm{MPa}$ rather than 50 , and $60^{\circ} \mathrm{C}$ rather than $40^{\circ} \mathrm{C}$. Thus, the employ of higher temperature studied in this case $\left(70{ }^{\circ} \mathrm{C}\right)$ seemed to interfere the polyphenol recover. The presence of polar solvents was reported to have a positive effect for the extraction of compounds from different natural products [50,51]. In fact, organic solvents with water are usually combined in the isolation of bioactive compounds from grapes and their by-products [52,53]. For instance, Kytrité et al. [54] studied the recovery of antioxidant compounds of lingoberry by different SFE techniques (SFE-PLE), among which PLE-ethanol offered better recoveries of polar compounds above PLE-water. Accordingly, PLE was evaluated as a potential technique for the extraction of polyphenols and anthocyanins. The extractions took place at the most convenient pressure and temperature conditions previously determined by ESE $\left(20 \mathrm{MPa}\right.$ and $\left.55^{\circ} \mathrm{C}\right)$ using different solvents. As can be seen (Figure 2), the use of $\mathrm{C}_{2} \mathrm{H}_{5} \mathrm{OH}: \mathrm{H}_{2} \mathrm{O}$ would favour a slightly greater extraction yield. This result agrees with the research of Santos et al. when recovering active compounds from feijoa peel [55]. Moreover, the antioxidant capacity of the RGPE obtained by means of PLE increases significantly, providing very much higher antioxidant extracts, due to the EC50 values are quite low, leading to think that the mixture of organic solvent and water promoted the extraction of the active compounds. According to Mustafa and Turner [56], the ethanol in this dual mixture could improve the solubility of the analyte, while the water would enhance its desorption and would break the matrixanalyte hydrogen bonding. Moreover, the presence of water could be an important factor for the extraction of glycosylated anthocyanins - as will be further discuss in Section 3.3.-, while the presence of ethanol decreases the water surface tension, favouring infiltration and mass transfer [56]. Corrales et al. [57] reported that the antioxidant capacity of RGPE obtained by PLE was specially enhanced by hydroalcoholic mixtures when ethanol content remained within the 50-80\% range. Similar conclusions were reported by Otero-Pareja [41] obtaining better RGPE by PLE at $10 \mathrm{MPa}$ and $120^{\circ} \mathrm{C}$. In agreement, Ferri et al. [58] reported a higher polyphenol extraction yield in RGPE of Merlot variety using PLE instead of solvent extraction using $\mathrm{C}_{2} \mathrm{H}_{5} \mathrm{OH}: \mathrm{H}_{2} \mathrm{O}$, although obtaining similar antioxidant activity. Alañon et al. studied the composition and bioactivity of wine by-products obtained by PLE, pointing the hydroalcoholic mixtures as better solvents for obtaining antioxidant and rich-in-phenolic compounds extracts [59]. Considering the results, the extract obtained by $\mathrm{PLE}$ at $20 \mathrm{MPa}$ and $55^{\circ} \mathrm{C}$ using $\mathrm{C}_{2} \mathrm{H}_{5} \mathrm{OH}: \mathrm{H}_{2} \mathrm{O}$ was used in impregnation experiments, and was characterized in terms of antibacterial capacity. 


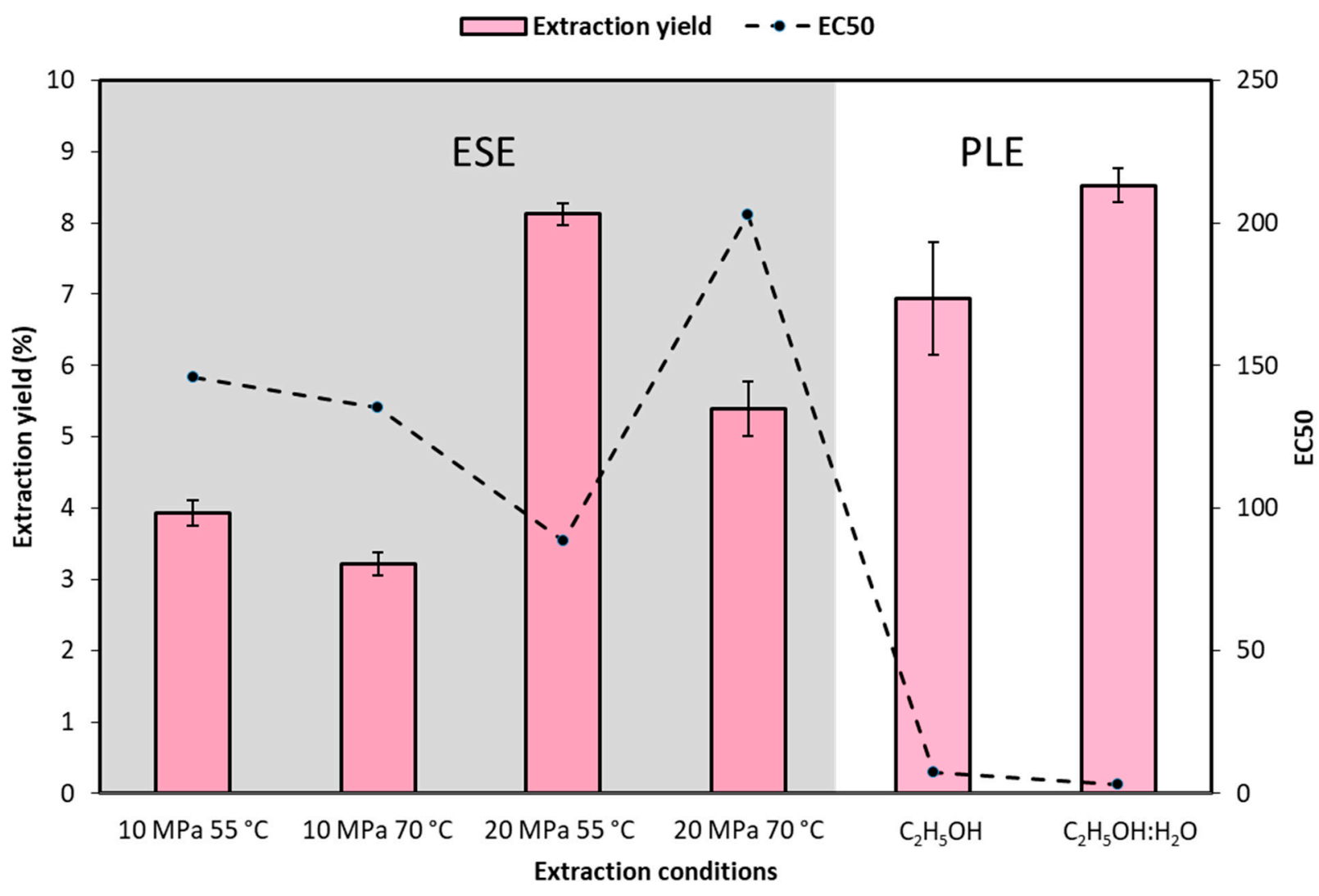

Figure 2. Extraction yield and antioxidant activity of the red grape pomace extracts (RGPE) obtained by ESE and PLE ( $n=2$ ).

Table 3 shows the Minimum Inhibitory Concentration (MIC) of RGPE against three common food pathogens. Escherichia coli was the most resistant bacteria to the presence of RGPE, with a MIC value of $12 \mathrm{mg} / \mathrm{mL}$ of RGPE, followed by Pseudomonas aeruginosa (4 mg/mL) and Staphylococcus aureus $(1.5 \mathrm{mg} / \mathrm{mL})$. Possibly, the double-lipid membrane of gram-negative bacteria makes them especially resistant to the action of some antibacterial substances [60]. The results obtained in this work are more satisfactory than other reported in literature. Respecting to the raw material, the grape variety influences the bioactivity of the extracts. Cheng et al. studied the antimicrobial activity of the grape pomace of Pinot noir and Pinot meunier [53], observing that $S$. aureus was also the most sensitive microorganism in all extracts studied, showing a MIC of 0.75 and 12.5 respectively in $\mathrm{C}_{2} \mathrm{H}_{5} \mathrm{OH}: \mathrm{H}_{2} \mathrm{O}$ extracts. Regarding to the extraction technique used, lower activity was found in Petit Verdot extracts obtained from the maceration of seeds and grape skin, where no antibacterial activity against E. coli was found, and S. aureus was inhibited only when using concentrations over $6.25 \mathrm{mg} / \mathrm{mL}$ [61]. In fact, Oliveira et al. [62] found lower antimicrobial activity in Syrah and Merlot grape pomace extracts obtained by SFE at $25 \mathrm{MPa}$ and $60{ }^{\circ} \mathrm{C}$, observing no inhibition against E. coli and P. aeruginosa so, again, it seemed more convenient the use of PLE technique instead of other SFE technique. The literature comparing antibacterial activity of grape by-products by different conditions of PLE is very scarce, but there are references using other natural extracts. For instance, Zandoná et al. [63] studied the antimicrobial activity of araçazeiro (Psidium cattleianum) leaf by PLE (10.3 MPa, $50{ }^{\circ} \mathrm{C}$ ) using different solvents, achieving higher inhibition of $S$. aureus and $P$. aeruginosa in water/ethanol mixtures rather than water or ethanol alone. All this information confirms the use of $\mathrm{C}_{2} \mathrm{H}_{5} \mathrm{OH}: \mathrm{H}_{2} \mathrm{O}$ mixtures by PLE as the most convenient alternative for their further use in the impregnation experiments. 
Table 3. Antibacterial activity of pure RGPE and IJF at $50 \mathrm{MPa} 55^{\circ} \mathrm{C}(n=2)$.

\begin{tabular}{cccc}
\hline \multirow{2}{*}{ Bacteria } & MIC RGPE $(\mathbf{m g} / \mathbf{m L})$ & $\begin{array}{c}\text { Concentration of } \\
\text { RGPE in Liquid } \\
\text { Medium }(\mathbf{m g} / \mathbf{L})\end{array}$ & $\begin{array}{c}\text { \% Inhibition in } \\
\text { RGPE-Jute }\end{array}$ \\
\hline \multirow{2}{*}{ Escherichia coli } & \multirow{2}{*}{12.0} & 0.07 & $8.250 \pm 0.496$ \\
Pseudomonas & \multirow{2}{*}{4.0} & 0.14 & $14.877 \pm 1.385$ \\
aeruginosa & \multirow{2}{*}{1.5} & 0.07 & $26.045 \pm 3.007$ \\
Staphylococcus aureus & & 0.14 & $35.471 \pm 1.516$ \\
\hline
\end{tabular}

\subsection{Bioactivity of RGPE-Impregnated Natural Fibers}

The aim of the supercritical impregnation is to include an active substance into a polymeric matrix in order to obtain a new material with active properties. To evaluate the bioactivity of the jute fabrics impregnated with RGPE, the impregnation yield, the antioxidant activity and the antibacterial activity were determined.

Three different experiments were carried out in order to evaluate the influence of the operational variables in the impregnation process (Figure 3). The first experiment was carried out using $2.8 \%$ of modifier $\left(\mathrm{C}_{2} \mathrm{H}_{5} \mathrm{OH}: \mathrm{H}_{2} \mathrm{O}(1: 1)\right)$ and $28.8 \mathrm{mg}$ of dried RGPE, to evaluate the influence of pressure variations on the process (Figure $3 \mathrm{~A}$ ). Greater pressure values provided impregnated natural fibers with higher RGPE loading and antioxidant capacity. When the pressure raises, the density of the supercritical fluid increases, which may favour both the swelling of the matrix and the solubility of the compounds. This behaviour agrees with the literature on the impregnation of polyester and cotton natural fibers with natural extracts, as well as on the impregnation of PET/PP films with natural extracts $[42,45,64]$. Based on these results, a pressure of $50 \mathrm{MPa}$ was selected for the experiments to be carried out later on.
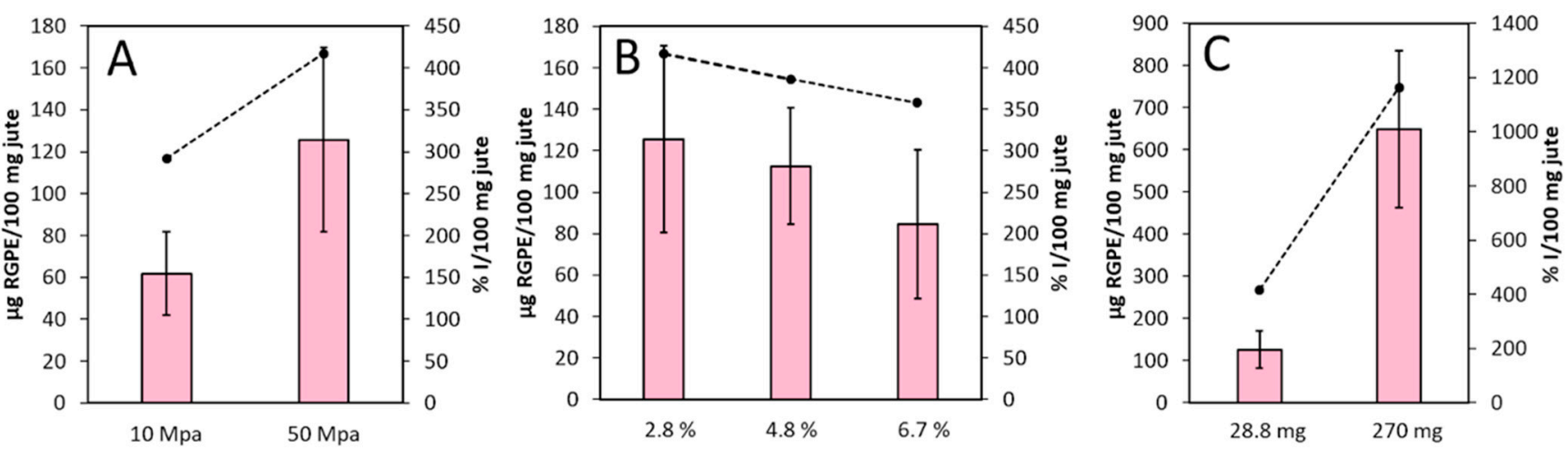

Figure 3. Influence of variables on the impregnation loading and the antioxidant capacity of the impregnated fabric samples $(n=2)$. (A) Effect of pressure (experiment 1). (B) Effect of modifier percentage (experiment 2). (C) Effect of dried RGPE loading (experiment 3).

In the second experiment, the modifier percentage introduced in the impregnation vessel was evaluated at a fixed RGPE concentration (Figure 3B). This factor was studied at three particular levels (i.e., 2.8, 4.8 and 6.7\%), while RGPE concentration remained constant $(9.6 \mathrm{mg} / \mathrm{mL})$. For this purpose, different amounts of dried RGPE were introduced in the vessel $(28.8,46.1$ and $67.2 \mathrm{mg}$ respectively). It was observed that an increase of the $\mathrm{C}_{2} \mathrm{H}_{5} \mathrm{OH}: \mathrm{H}_{2} \mathrm{O}$ percentage had in general a negative effect on the impregnation loading while the best results were obtained with a modifier percentage of $2.8 \%$, although no differences were found between using 2.8 and $4.8 \%$. It has been reported that the relation 
$\mathrm{CO}_{2} /$ modifier, as well as the nature of the modifier, interfere in the affinity between the solute and the matrix [64]. For instance, García-Casas and others established that $10 \% v / v$ of acetone/DMSO $(80 \% / 20 \%) / \mathrm{CO}_{2}$ were the optimal conditions to impregnate mangiferin into silica [65]. The characteristics of the supercritical phase varied according to the percentage of modifier used. When increasing, the affinity between the solute and the supercritical phase seemed to increase, which eventually reduced the impregnation loading. Besides, the presence of water in the modifier could further evidence this change of affinity. The low solubility of water in $\mathrm{scCO}_{2}$ could lead to the formation of a second phase in the solvent [66], which may further alter the balance solute-fluid-matrix at higher modifier percentages. Regarding the effect of the modifier on the matrix, it has been reported that a higher modifier content increases the swelling effect of supercritical $\mathrm{CO}_{2}$ on polymers [67], which favours the impregnation of compounds. As far as we know, any literature of the swelling effect on jute natural fibers under supercritical conditions has been ever reported. Yet, such effect did not seem to be predominant in the impregnation efficiency. On the contrary, the amount of dried extract introduced in the vessel at a fixed modifier percentage showed a high relevance (Figure 3). When a greater amount of extract was used, the impregnation loading and the antioxidant capacity of the natural fibers increased considerably. Possibly, the supercritical phase was more concentrated in compounds and the system tended to balance by impregnating the matrix, producing natural fibers with a higher bioactivity. As far as we know, any similar results have been reported in natural fibers, although, some experiments carried out in polymers achieved the same conclusion. For instance, Wenzel et al. obtained better loading of walnut husk ethanolic extract in impregnated LDPE films when its concentration increased 1g/g ethanol [68]. Moreover, previous experiments with olive leaf extract impregnated into PET/PP polymer achieved the same conclusion [69], although the significance was not as evident as in this case, probably because of the high affinity between RGPE and the jute natural fibers.

Considering the results obtained, it was determined that the best impregnation conditions were $50 \mathrm{MPa}$ and $55^{\circ} \mathrm{C}$, using a RGPE with $2.8 \%$ of $\mathrm{C}_{2} \mathrm{H}_{5} \mathrm{OH}: \mathrm{H}_{2} \mathrm{O}$ and $270 \mathrm{mg}$ of dried RGPE. The IJF used for the antibacterial assay was obtained at such optimal conditions.

Different pathogenic bacteria were cultivated in liquid LB medium in the presence of two amounts of impregnated natural fibers $(50 \mathrm{and} 100 \mathrm{mg}$ ) that resulted in a corresponding RPGE concentration in the culture media of 0.07 and $0.14 \mathrm{mg}$ RGPE/mL respectively. This concentration of RGPE in the media was far below the MIC values reached by crude RGPE (Table 3) and too low to totally inhibit the growth of microorganisms. However, the natural fiber showed higher growth inhibition that would be expected, which might be due to a reduction in the RGPE particle size or by a selective impregnation of the RGPE compounds with greater antibacterial capacity. This behaviour had been previously observed when the antibacterial capacity of olive leaf extract against $P$. aeruginosa before and after its impregnation in PET/PP films [69].

\subsection{Phenolic Composition of RGPE and Impregnated Jute Fiber}

The quantification of the identified compounds is collected in Table 4. Eleven phenolic compounds were identified in the RGPE obtained by PLE using $\mathrm{C}_{2} \mathrm{H}_{5} \mathrm{OH}: \mathrm{H}_{2} \mathrm{O}$ as extraction solvent. The abundance of flavonols is representative in the extract, which is in agreement to Jara-Palacios et al. [70], who found the quercetin-3-O-glucoside as the most abundant compound identified in a $\mathrm{C}_{2} \mathrm{H}_{5} \mathrm{OH}: \mathrm{H}_{2} \mathrm{O}$ RGPE. On the other hand, it has been reported a great amount of catechin in GPE obtained by subcritical water extraction at $100 \mathrm{MPa}$ at different temperature ranges [71]. In this case, although catequin is not the most abundant compound, it has demonstrated the highest affinity both with the supercritical phase and the fibers during impregnation, and it has been successfully loaded in the fibers. 
Table 4. Phenolic composition of RGPE and impregnated jute fibers $(n=2)$.

\begin{tabular}{|c|c|c|c|c|c|}
\hline & RT & Mass (Da) & RGPE ( $\mu \mathrm{g} / \mathrm{mL})$ & IJF $(\mu \mathrm{g} / \mathrm{mL})$ & $\%$ Impregnation * \\
\hline \multicolumn{6}{|l|}{ Phenolic acids } \\
\hline Protocatechuic acid & 0.38 & 153.0188 & $1.45 \pm 0.09$ & $5.38 \pm 0.71$ & $6.60 \pm 0.47$ \\
\hline Caffeic acid & 1.81 & 179.0344 & $0.63 \pm 0.90$ & nd & nd \\
\hline$p$-coumaric acid & 1.95 & 163.0395 & $1.27 \pm 0.50$ & $22.56 \pm 3.46$ & $33.08 \pm 8.19$ \\
\hline Syringic acid & 1.98 & 197.0450 & $17.70 \pm 1.35$ & $22.73 \pm 1.31$ & $2.29 \pm 0.31$ \\
\hline \multicolumn{6}{|l|}{ Flavanols } \\
\hline Catechin & 2.59 & 289.0712 & $0.73 \pm 0.04$ & $20.08 \pm 1.69$ & $48.77 \pm 1.63$ \\
\hline \multicolumn{6}{|l|}{ Flavonols } \\
\hline Rutin & 1.94 & 609.1456 & $10.03 \pm 3.60$ & nd & nd \\
\hline Quercetin 3-glucoside & 1.98 & 463.0877 & $43.62 \pm 7.90$ & nd & nd \\
\hline Quercetin & 2.31 & 301.0348 & $20.12 \pm 1.26$ & nd & nd \\
\hline \multicolumn{6}{|l|}{ Anthocyanins } \\
\hline Delphinidin-3-O-glucoside & 1.98 & 463.0877 & $86.28 \pm 2.04$ & nd & nd \\
\hline Petunidin-3-O-glucoside & 2.07 & 477.1033 & $20.99 \pm 4.89$ & nd & nd \\
\hline Delphinidin 3-O-(6"-acetyl)-glucoside & 2.15 & 505.0982 & $8.27 \pm 0.30$ & nd & nd \\
\hline
\end{tabular}

* calculated as $\mu \mathrm{g}$ compound contained in the extract/ $\mu \mathrm{g}$ compound in the fabric.

From the RGPE compounds identified, only four have been found in the IJF, which evidence the selective character of the impregnation process, being especially selective to phenolic acids. Syringic, $p$-coumaric and protocatechuic acids were the most abundant compounds in impregnated fibers at the condition studied, being the responsible for their bioactivity. Regarding flavanols, only catechin was found in the impregnated fibers. The process was less selective to anthocyanins, and any of them was identified in the jute fabric. According to the results obtained by Buratto and researchers in the supercritical drying of aerogels impregnated with hydroalcoholic açai extract, polyphenols were lower affine to the supercritical phase than anthocyanins, promoting its impregnation. Therefore, anthocyanins were dragged out of the system and its remaining content in the dry aerogel was very low [72]. Possibly, this behavior also occurs in the jute impregnation, and the process was more selective in low-weight phenolic compounds, since significant content of catechin and $p$-coumaric acid were determined in IJF. Those compounds have been reported to have a high antioxidant and antimicrobial activity against food pathogens, such as Staphylococcus aureus, E. coli and B. cereus, which confirms the results obtained in terms of the bioactivity observed in both the fabrics and the extracts $[73,74]$.

\subsection{SEM Images}

Samples were evaluated by SEM in order to determine the distribution and the appearance of the extract in the natural fiber. SEM images at different magnifications are depicted in Figure 4.
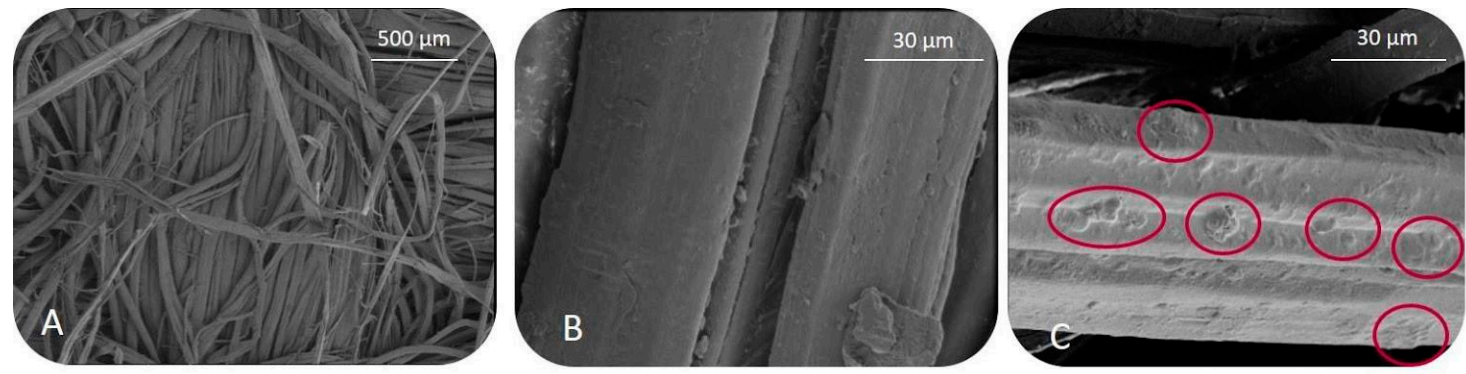

Figure 4. SEM images for non-impregnated (A,B) and impregnated RGPE jute fibers at (C). The red circles indicate the RGPE particles on the fabric surface. 
The impregnated natural fiber (Figure 4C) showed a more rugged surface in comparison with the one of the untreated natural fiber (Figure 4A y Figure 4B), observing a partial penetration of the RGPE particles into the fibers and thus, the great affinity between RGPE and the fibers on the impregnation process. This result agrees with previous literature about the impregnation of mango leaf extract into natural cotton natural fibers, where spherical particles embedded into the fibers were observed [75].

\section{Conclusions}

The promising prospects in the production of active food packaging using agriculture by-products as active agents, opens a new way for the revalorization of such by-products. The RGP that is obtained after the vinification process still contains a large amount of bioactive compounds that can be put to some use after being extracted. Moreover, the solid residues after such extraction could be still used for other applications based on its protein, fiber or carbohydrate contents among others, where this target compound would be an intermediate product.

Regarding the production of RGPE, PLE using $\mathrm{C}_{2} \mathrm{H}_{5} \mathrm{OH}: \mathrm{H}_{2} \mathrm{O}$ as the solvent seemed to be the best choice to obtain an extract with high antioxidant and antibacterial capacities. In view of the results, the antioxidant and antimicrobial properties of RGPE were transferred successfully to jute natural fabrics through supercritical impregnation. These results are comparable with other obtained in polymeric matrices, and offer a very encouraging view of the use of this natural fiber as active food packaging.

Author Contributions: Writing — original draft preparation, methodology, validation and data curation, C.C.-B.; formal analysis and investigation, P.A.-M.; methodology, M.T.F.-P.; supervision and writing-review and editing, L.C. and C.M.; funding acquisition, E.J.M.d.l.O. and C.P. All authors have read and agreed to the published version of the manuscript.

Funding: This research was funded by Spanish Ministry of Science and Technology, Project CTQ201786661-R and European Regional Development Fund (ERDF).

Institutional Review Board Statement: Not applicable.

Informed Consent Statement: Not applicable.

Data Availability Statement: All the data presented in this study are available in this article.

Acknowledgments: The authors acknowledge the Spanish Ministry of Science and Technology (Project CTQ2017-86661-R) and European Regional Development Fund (ERDF) for the financial support. Authors also thank the Central Services of UCA for the chromatographic analysis.

Conflicts of Interest: The authors declare no conflict of interest. The funders had no role in the design of the study; in the collection, analyses, or interpretation of data; in the writing of the manuscript, or in the decision to publish the results.

\section{References}

1. Meini, M.-R.; Cabezudo, I.; Boschetti, C.E.; Romanini, D. Recovery of phenolic antioxidants from syrah grape pomace through the optimization of an enzymatic extraction process. Food Chem. 2019, 283, 257-264. [CrossRef]

2. González-Centeno, M.R.; Knoerzer, K.; Sabarez, H.; Simal, S.; Rosselló, C.; Femenia, A. Effect of acoustic frequency and power density on the aqueous ultrasonic-assisted extraction of grape pomace (Vitis vinifera L.)-A response surface approach. Ultrason. Sonochem. 2014, 21, 2176-2184. [CrossRef]

3. Oladele, A.K.; Duodu, K.G.; Emmambux, N.M. Pasting, flow, thermal and molecular properties of maize starch modified with crude phenolic extracts from grape pomace and sorghum bran under alkaline conditions. Food Chem. 2019, 297, 124879. [CrossRef]

4. Trikas, E.D.; Melidou, M.; Papi, R.M.; Zachariadis, G.A.; Kyriakidis, D.A. Extraction, separation and identification of anthocyanins from red wine by-product and their biological activities. J. Funct. Foods 2016, 25, 548-558. [CrossRef]

5. Mohd Maidin, N.; Michael, N.; Oruna-Concha, M.J.; Jauregi, P. Polyphenols extracted from red grape pomace by a surfactant based method show enhanced collagenase and elastase inhibitory activity. J. Chem. Technol. Biotechnol. 2018, 93, $1916-1924$. [CrossRef]

6. Andrés, A.I.; Petrón, M.J.; Adámez, J.D.; López, M.; Timón, M.L. Food by-products as potential antioxidant and antimicrobial additives in chill stored raw lamb patties. Meat Sci. 2017, 129, 62-70. [CrossRef] [PubMed] 
7. Garrido, M.D.; Auqui, M.; Martí, N.; Linares, M.B. Effect of two different red grape pomace extracts obtained under different extraction systems on meat quality of pork burgers. LWT Food Sci. Technol. 2011, 44, 2238-2243. [CrossRef]

8. Kafantaris, I.; Stagos, D.; Kotsampasi, B.; Hatzis, A.; Kypriotakis, A.; Gerasopoulos, K.; Makri, S.; Goutzourelas, N.; Mitsagga, C.; Giavasis, I.; et al. Grape pomace improves performance, antioxidant status, fecal microbiota and meat quality of piglets. Animal 2018, 12, 246-255. [CrossRef] [PubMed]

9. Baaka, N.; Ben Ticha, M.; Haddar, W.; Amorim, M.T.P.; Mhenni, M.F. Upgrading of uv protection properties of several textile fabrics by their dyeing with grape pomace colorants. Fibers Polym. 2018, 19, 307-312. [CrossRef]

10. Karaboyacı, M.; Uğur, S..S. Ecological wool dyeing with pulps of lavender, broom, and red wine. J. Text. Inst. 2014, 105, 821-827. [CrossRef]

11. Mansour, R.; Ezzili, B.; Farouk, M. The use of response surface method to optimize the extraction of natural dye from winery waste in textile dyeing. J. Text. Inst. 2017, 108, 528-537. [CrossRef]

12. Choi, I.; Lee, J.Y.; Lacroix, M.; Han, J. Intelligent ph indicator film composed of agar/potato starch and anthocyanin extracts from purple sweet potato. Food Chem. 2017, 218, 122-128. [CrossRef]

13. Liang, S.; Wang, L. A natural antibacterial-antioxidant film from soy protein isolate incorporated with cortex phellodendron extract. Polymers 2018, 10, 71. [CrossRef] [PubMed]

14. Liu, Y.; Qin, Y.; Bai, R.; Zhang, X.; Yuan, L.; Liu, J. Preparation of ph-sensitive and antioxidant packaging films based on K-carrageenan and mulberry polyphenolic extract. Int. J. Biol. Macromol. 2019, 134, 993-1001. [CrossRef] [PubMed]

15. Yong, H.; Liu, J. Recent advances in the preparation, physical and functional properties, and applications of anthocyanins-based active and intelligent packaging films. Food Packag. Shelf Life 2020, 26, 100550. [CrossRef]

16. Kurek, M.; Hlupić, L.; Elez Garofulić, I.; Descours, E.; Ščetar, M.; Galić, K. Comparison of protective supports and antioxidative capacity of two bio-based films with revalorised fruit pomaces extracted from blueberry and red grape skin. Food Packag. Shelf Life 2019, 20, 100315. [CrossRef]

17. Bi, F.; Zhang, X.; Bai, R.; Liu, Y.; Liu, J.; Liu, J. Preparation and characterization of antioxidant and antimicrobial packaging films based on chitosan and proanthocyanidins. Int. J. Biol. Macromol. 2019, 134, 11-19. [CrossRef]

18. Qin, Y.; Liu, Y.; Yuan, L.; Yong, H.; Liu, J. Preparation and characterization of antioxidant, antimicrobial and ph-sensitive films based on chitosan, silver nanoparticles and purple corn extract. Food Hydrocoll. 2019, 96, 102-111. [CrossRef]

19. Qin, Y.; Liu, Y.; Yong, H.; Liu, J.; Zhang, X.; Liu, J. Preparation and characterization of active and intelligent packaging films based on cassava starch and anthocyanins from lycium ruthenicum murr. Int. J. Biol. Macromol. 2019, 134, 80-90. [CrossRef]

20. Xu, Y.; Willis, S.; Jordan, K.; Sismour, E. Chitosan nanocomposite films incorporating cellulose nanocrystals and grape pomace extracts. Packag. Technol. Sci. 2018, 31, 631-638. [CrossRef]

21. Vidal, G.; Hormazabal, S. Las Fibras Vegetales y sus Aplicaciones. Innovación en su Generación a Partir de la Depuración de Agua; Universidad de Concepción: Concepción, Chile, 2016.

22. Yashas Gowda, T.G.; Sanjay, M.R.; Subrahmanya Bhat, K.; Madhu, P.; Senthamaraikannan, P.; Yogesha, B. Polymer matrix-natural fiber composites: An overview. Cogent Eng. 2018, 5, 1446667. [CrossRef]

23. Ivanovic, J.; Milovanovic, S.; Stamenic, M.; Fanovich, M.A.; Jaeger, P.; Zizovic, I. Application of an integrated supercritical extraction and impregnation process for incorporation of thyme extracts into different carriers. In Handbook on Supercritical Fluids: Fundamentals, Properties and Applications; Osborne, J., Ed.; Nova Science Publishers: New York, NY, USA, $2014 ;$ pp. 258-280.

24. Binti Mohd Nor Hamin, N.S.; Sahadan, M.Y.; Rozman, N.A.S.; Wen Nee, T.; Woei Yenn, T.; Zahan, K.A.; Suzana, W.; Chean Ring, L. Development of medical cotton fabrics with punica granatum 1 extract finishing for nosocomial infections control. J. Nat. Fibers 2019, 16, 404-411. [CrossRef]

25. Sharaf, S.; Higazy, A.; Hebeish, A. Propolis induced antibacterial activity and other technical properties of cotton textiles. Int. J. Biol. Macromol. 2013, 59, 408-416. [CrossRef] [PubMed]

26. Studer, J.; Dransfeld, C.; Jauregui Cano, J.; Keller, A.; Wink, M.; Masania, K.; Fiedler, B. Effect of fabric architecture, compaction and permeability on through thickness thermoplastic melt impregnation. Compos. Part A Appl. Sci. Manuf. 2019, 122, 45-53. [CrossRef]

27. Lau, K.-t.; Hung, P.-y.; Zhu, M.-H.; Hui, D. Properties of natural fibre composites for structural engineering applications. Compos. Part B Eng. 2018, 136, 222-233. [CrossRef]

28. Majeed, K.; Jawaid, M.; Hassan, A.; Abu Bakar, A.; Abdul Khalil, H.P.S.; Salema, A.A.; Inuwa, I. Potential materials for food packaging from nanoclay/natural fibres filled hybrid composites. Mater. Des. 2013, 46, 391-410. [CrossRef]

29. Chan, K.-Y.; Jia, B.; Lin, H.; Hameed, N.; Lee, J.-H.; Lau, K.-T. A critical review on multifunctional composites as structural capacitors for energy storage. Compos. Struct. 2018, 188, 126-142. [CrossRef]

30. Jawaid, M.; Khalil, H.P.S.A.; Bakar, A.A.; Khanam, P.N. Chemical resistance, void content and tensile properties of oil palm/jute fibre reinforced polymer hybrid composites. Mater. Des. 2011, 32, 1014-1019. [CrossRef]

31. Gangopadhyay, U.K.; Mathur, M.R.; Singh, R.P. Moisture managing technical textiles for packaging of horticultural products. Man-Made Text. India 2018, 46, 259-262.

32. Chatterjee, A.; Kumar, S.; Singh, H. Tensile strength and thermal behavior of jute fibre reinforced polypropylene laminate composite. Compos. Commun. 2020, 22, 100483. [CrossRef]

33. Cejudo Bastante, C.; Casas Cardoso, L.; Mantell Serrano, C.; Martínez de la Ossa, E.J. Supercritical impregnation of food packaging films to provide antioxidant properties. J. Supercrit. Fluids 2017, 128, 200-207. [CrossRef] 
34. Fanovich, M.A.; Ivanovic, J.; Zizovic, I.; Misic, D.; Jaeger, P. Functionalization of polycaprolactone/hydroxyapatite scaffolds with usnea lethariiformis extract by using supercritical co2. Mater. Sci. Eng. C 2016, 58, 204-212. [CrossRef] [PubMed]

35. Maksimovic, S.; Tadic, V.; Ivanovic, J.; Radmanovic, T.; Milovanovic, S.; Stankovic, M.; Zizovic, I. Utilization of the integrated process of supercritical extraction and impregnation for incorporation of helichrysum italicum extract into corn starch xerogel. Chem. Ind. Chem. Eng. Q. 2018, 24, 191-200. [CrossRef]

36. Milovanovic, S.; Hollermann, G.; Errenst, C.; Pajnik, J.; Frerich, S.; Kroll, S.; Rezwan, K.; Ivanovic, J. Supercritical co2 impregnation of pla/pcl films with natural substances for bacterial growth control in food packaging. Food Res. Int. 2018, 107, 486-495. [CrossRef] [PubMed]

37. Medeiros, G.R.; Ferreira, S.R.S.; Carciofi, B.A.M. High pressure carbon dioxide for impregnation of clove essential oil in lldpe films. Innov. Food Sci. Emerg. Technol. 2017, 41, 206-215. [CrossRef]

38. Medeiros, G.R.; Guimarães, C.; Ferreira, S.R.S.; Carciofi, B.A.M. Thermomechanical and transport properties of lldpe films impregnated with clove essential oil by high-pressure $\mathrm{CO}_{2}$. J. Supercrit. Fluids 2018, 139, 8-18. [CrossRef]

39. Almeida, A.P.; Rodríguez-Rojo, S.; Serra, A.T.; Vila-Real, H.; Simplicio, A.L.; Delgadilho, I.; Beirão Da Costa, S.; Beirão Da Costa, L.; Nogueira, I.D.; Duarte, C.M.M. Microencapsulation of oregano essential oil in starch-based materials using supercritical fluid technology. Innov. Food Sci. Emerg. Technol. 2013, 20, 140-145. [CrossRef]

40. Pires, F.C.S.; e Silva, A.P.D.S.; Salazar, M.D.L.A.R.; da Costa, W.A.; da Costa, H.S.C.; Lopes, A.S.; Rogez, H.; de Carvalho Junior, R.N. Determination of process parameters and bioactive properties of the murici pulp (byrsonima crassifolia) extracts obtained by supercritical extraction. J. Supercrit. Fluids 2019, 146, 128-135. [CrossRef]

41. Otero-Pareja, M.J.; Casas, L.; Fernández-Ponce, M.T.; Mantell, C.; De La Ossa, E.J.M. Green extraction of antioxidants from different varieties of red grape pomace. Molecules 2015, 20, 9686-9702. [CrossRef]

42. Sanchez-Sanchez, J.; Fernández-Ponce, M.T.; Casas, L.; Mantell, C.; de la Ossa, E.J.M. Impregnation of mango leaf extract into a polyester textile using supercritical carbon dioxide. J. Supercrit. Fluids 2017, 128, 208-217. [CrossRef]

43. Brand-Williams, W.; Cuvelier, M.E.; Berset, C. Use of a free radical method to evaluate antioxidant activity. LWT Food Sci. Technol. 1995, 28, 25-30. [CrossRef]

44. Scherer, R.; Godoy, H.T. Antioxidant activity index (aai) by the 2,2-diphenyl-1-picrylhydrazyl method. Food Chem. 2009, 112, 654-658. [CrossRef]

45. Cejudo Bastante, C.; Casas Cardoso, L.; Fernández Ponce, M.T.; Mantell Serrano, C.M.; de la Ossa-Fernández, E.J. Characterization of olive leaf extract polyphenols loaded by supercritical solvent impregnation into pet/pp food packaging films. J. Supercrit. Fluids 2018, 140, 196-206. [CrossRef]

46. de Peredo AV, G.; Vázquez-Espinosa, M.; Piñeiro, Z.; Espada-Bellido, E.; Ferreiro-González, M.; Barbero, G.F.; Palma, M. Development of a rapid and accurate uhplc-pda-fl method for the quantification of phenolic compounds in grapes. Food Chem. 2021, 334, 127569. [CrossRef] [PubMed]

47. Tamires Vitor Pereira, D.; Vollet Marson, G.; Fernández Barbero, G.; Gadioli Tarone, A.; Baú Betim Cazarin, C.; Dupas Hubinger, M.; Martínez, J. Concentration of bioactive compounds from grape marc using pressurized liquid extraction followed by integrated membrane processes. Sep. Purif. Technol. 2020, 250, 117206. [CrossRef]

48. Pöhler, H.; Kiran, E. Volumetric properties of carbon dioxide + ethanol at high pressures. J. Chem. Eng. Data 1997, 42, 384-388. [CrossRef]

49. Mantell, C.; Rodríguez, M.; Martínez de la Ossa, E. A screening analysis of the high-pressure extraction of anthocyanins from red grape pomace with carbon dioxide and cosolvent. Eng. Life Sci. 2003, 3, 38-42. [CrossRef]

50. Casazza, A.A.; Aliakbarian, B.; Sannita, E.; Perego, P. High-pressure high-temperature extraction of phenolic compounds from grape skins. Int. J. Food Sci. Technol. 2012, 47, 399-405. [CrossRef]

51. Luque-Rodríguez, J.M.; Luque de Castro, M.D.; Pérez-Juan, P. Dynamic superheated liquid extraction of anthocyanins and other phenolics from red grape skins of winemaking residues. Bioresour. Technol. 2007, 98, 2705-2713.

52. Simonetti, G.; Brasili, E. Antifungal activity of phenolic and polyphenolic compounds from different matrices of Vitis vinifera L. Against human pathogens. Molecules 2020, 25, 3748. [CrossRef]

53. Cheng, V.J.; Bekhit, A.E.-D.A.; McConnell, M.; Mros, S.; Zhao, J. Effect of extraction solvent, waste fraction and grape variety on the antimicrobial and antioxidant activities of extracts from wine residue from cool climate. Food Chem. 2012, 134, 474-482. [CrossRef]

54. Kitrytè, V.; Kavaliauskaitè, A.; Tamkutè, L.; Pukalskienè, M.; Syrpas, M.; Rimantas Venskutonis, P. Zero waste biorefining of lingonberry (Vaccinium vitis-idaea L.) pomace into functional ingredients by consecutive high pressure and enzyme assisted extractions with green solvents. Food Chem. 2020, 322, 126767. [CrossRef] [PubMed]

55. Santos, P.H.; Baggio Ribeiro, D.H.; Micke, G.A.; Vitali, L.; Hense, H. Extraction of bioactive compounds from feijoa (acca sellowiana (o. Berg) burret) peel by low and high-pressure techniques. J. Supercrit. Fluids 2019, 145, 219-227. [CrossRef]

56. del Valle, J.M.; Martín, Á.; Cocero, M.J.; de la Fuente, J.C.; de la Cruz-Quiroz, R. Supercritical co2 extraction of solids using aqueous ethanol as static modifier is a two-step mass transfer process. J. Supercrit. Fluids 2019, 143, 179-190. [CrossRef]

57. Corrales, M.; García, A.F.; Butz, P.; Tauscher, B. Extraction of anthocyanins from grape skins assisted by high hydrostatic pressure. J. Food Eng. 2009, 90, 415-421. [CrossRef] 
58. Ferri, M.; Vannini, M.; Ehrnell, M.; Eliasson, L.; Xanthakis, E.; Monari, S.; Sisti, L.; Marchese, P.; Celli, A.; Tassoni, A. From winery waste to bioactive compounds and new polymeric biocomposites: A contribution to the circular economy concept. J. Adv. Res. 2020, 24, 1-11. [CrossRef] [PubMed]

59. Alañón, M.E.; Alarcón, M.; Marchante, L.; Díaz-Maroto, M.C.; Pérez-Coello, M.S. Extraction of natural flavorings with antioxidant capacity from cooperage by-products by green extraction procedure with subcritical fluids. Ind. Crops Prod. 2017, 103, 222-232. [CrossRef]

60. Ghai, I.; Ghai, S. Understanding antibiotic resistance via outer membrane permeability. Infect. Drug Resist. 2018, 11, 523-530. [CrossRef]

61. Martin, J.G.P.; Porto, E.; Corrêa, C.B.; Alencar, S.M.; Gloria, E.M.; Cabral, I.S.R.; Aquino, L.M. Antimicrobial potential and chemical composition of agro-industrial wastes. J. Natural Prod. 2012, 5, $27-36$.

62. Oliveira, D.A.; Salvador, A.A.; Smânia, A.; Smânia, E.F.A.; Maraschin, M.; Ferreira, S.R.S. Antimicrobial activity and composition profile of grape (Vitis vinifera) pomace extracts obtained by supercritical fluids. J. Biotechnol. 2013, 164, 423-432. [CrossRef]

63. Zandoná, G.P.; Bagatini, L.; Woloszyn, N.; de Souza Cardoso, J.; Hoffmann, J.F.; Moroni, L.S.; Stefanello, F.M.; Junges, A.; Rombaldi, C.V. Extraction and characterization of phytochemical compounds from araçazeiro (Psidium cattleianum) leaf: Putative antioxidant and antimicrobial properties. Food Res. Int. 2020, 137, 109573. [CrossRef] [PubMed]

64. Cejudo Bastante, C.; Cran, M.J.; Casas Cardoso, L.; Mantell Serrano, C.; Martínez de la Ossa, E.J.; Bigger, S.W. Effect of supercritical $\mathrm{co} 2$ and olive leaf extract on the structural, thermal and mechanical properties of an impregnated food packaging film. J. Supercrit. Fluids 2019, 145, 181-191. [CrossRef]

65. García-Casas, I.; Montes, A.; Valor, D.; Pereyra, C.; Martínez de la Ossa, E.J. Impregnation of mesoporous silica with mangiferin using supercritical co2. J. Supercrit. Fluids 2018, 140, 129-136. [CrossRef]

66. Kühn, S.; Temelli, F. Recovery of bioactive compounds from cranberry pomace using ternary mixtures of co2+ethanol+water. J. Supercrit. Fluids 2017, 130, 147-155. [CrossRef]

67. Champeau, M.; Thomassin, J.M.; Tassaing, T.; Jérôme, C. Drug loading of polymer implants by supercritical co2 assisted impregnation: A review. J. Control. Release 2015, 209, 248-259. [CrossRef]

68. Wenzel, J.E.; Moorman, V.; Wang, L.; Spencer-Williams, I.; Hall, M.; Samaniego, C.S.; Ammerman, M.L. In-situ extraction and impregnation of black walnut husk into polyethylene film using supercritical carbon dioxide with an ethanol modifier. Food Sci. Nutr. 2020, 8, 612-619. [CrossRef]

69. Cejudo Bastante, C.; Casas Cardoso, L.; Fernández-Ponce, M.T.; Mantell Serrano, C.; Martínez de la Ossa, E.J. Supercritical impregnation of olive leaf extract to obtain bioactive films effective in cherry tomato preservation. Food Packag. Shelf Life 2019, 21, 100338. [CrossRef]

70. Jara-Palacios, M.J.; Gonçalves, S. Extraction of antioxidants from winemaking byproducts: Effect of the solvent on phenolic composition, antioxidant and anti-cholinesterase activities, and electrochemical behaviour. Antioxidants 2020, 9, 675. [CrossRef]

71. Loarce, L.; Oliver-Simancas, R.; Marchante, L.; Díaz-Maroto, M.C.; Alañón, M.E. Implementation of subcritical water extraction with natural deep eutectic solvents for sustainable extraction of phenolic compounds from winemaking by-products. Food Res. Int. 2020, 137, 109728. [CrossRef]

72. Buratto, R.T.; Hoyos, E.G.; Cocero, M.J.; Martín, Á. Impregnation of açaí residue extracts in silica-aerogel. J. Supercrit. Fluids 2019, 146, 120-127. [CrossRef]

73. Ghazy, O.A.; Fouad, M.T.; Saleh, H.H.; Kholif, A.E.; Morsy, T.A. Ultrasound-assisted preparation of anise extract nanoemulsion and its bioactivity against different pathogenic bacteria. Food Chem. 2021, 341, 128259. [CrossRef] [PubMed]

74. Gómez-Mejía, E.; Roriz, C.L.; Heleno, S.A.; Calhelha, R.; Dias, M.I.; Pinela, J.; Rosales-Conrado, N.; León-González, M.E.; Ferreira, I.C.F.R.; Barros, L. Valorisation of black mulberry and grape seeds: Chemical characterization and bioactive potential. Food Chem. 2021, 337, 127998. [CrossRef] [PubMed]

75. Fernández-Ponce, M.T.; Medina-Ruiz, E.; Casas, L.; Mantell, C.; Martínez de la Ossa-Fernández, E.J. Development of cotton fabric impregnated with antioxidant mango polyphenols by means of supercritical fluids. J. Supercrit. Fluids 2018, 140, 310-319. [CrossRef] 